\title{
What is the most effective mouthwash in patients infected with covid-19 to minimize possible transmission by saliva? Update.
}

Juan Antonio Ruiz Roca*

Assistant Professor, Faculty of Dentistry, Department of Dermatology, Stomatology and Radiology. University of Murcia, Spain.

${ }^{\star}$ Corresponding author: Juan Antonio Ruiz Roca, Unit Special Patients and Gerodontology, Hospital Morales Meseguer, Avda, Marqués de los Vélez s/n, Murcia 30007, Spain; Tel: 0034/666858349; E-mail: jaruizroca@um.es

Received: April 06, 2020; Accepted: April 13, 2020; Published: April 17, 2020

\begin{abstract}
Objectives: To study if some antiseptic agent rinse can reduce the viral load of COVID-19 in the infected patients to minimize its virulence in respiratory tract, and therefore the contagious.

Materials and Methods: To analyze of scientific articles published in the last months, about the use and effectivity of some mouthwash against COVID-19 and write an update.
\end{abstract}

Results: Rinses, as an adjunctive measure for containing the COVID-19 transmission, are important to keep in mind, but there are very few articles on COVID-19 that cover mouthwashes.

Conclusions: A concentration of $1 \%-1.5 \%$ hydrogen peroxide solution or $1 \%-0.2 \%$ povidone-iodine seem to be an effective mouthwash to reduce the viral load in oral cavity of COVID-19.

Clinical Relevance: Due to COVID-19 pandemic, we are suffering, and growing information about this virus, questions about which antiseptic rinse to use to decrease the viral load is essential.

Keywords: COVID-19; dentistry, chlorhexidine, povidone iodine, antimicrobial mouth rinse, antimicrobial mouthwash

\section{Introduction}

The zoonotic virus named 2019-nCoV or COVID-19, belongs to the Coronaviridae family, it is probably outbreakstarted with Chinese horseshoe bats (Rhinolophus sinicus) [1], and although pangolism was initially thought of the most likely intermediate host [2], the publication on 20th February 2020 of the genetic analysis on the BioRxiv Server has showed that the conclusion was rushed.

An epidemic of coronavirus disease started in 2019, in Wuhan (China), and during a short period of time it is causing an outbreak of pneumonia known as severe acute respiratory syndrome coronavirus 2 (SARS- CoV-2) [3, 4].

From 31th December 2019 to 18th April 2020, 2197593 cases of COVID-19 have been reported (in accordance with the applied case definitions and testing strategies in the affected countries), including 153090 deaths (191726 infected, and 20043 deaths in Spain), and it has been recognized in 207 countries and territories around the world $[5,6]$, and the worst is that the number of confirmed cases and deaths continues increasing until today [3].

The predominant expression of ACE2 in the lower respiratory tract is believed to have determined the natural history of SARS as a lower respiratory tract infection. All patients were initially diagnosed by RT-PCR from oro- or nasopharyngeal swab specimens [7].

Nasopharyngeal and oropharyngeal samples were collected throughout the clinical course in all infected patients, with no statistically significant differences found in either viral loads or detection rates between the two samples. The earliest swabs were taken on first day of symptoms, with symptoms often being very mild or prodromal. All swabs from all patients taken between days 1 to 5 tested positive. The average virus RNA load was 6.76x105 copies per whole swab until day 5 (maximum, 7.11X108 copies/swab). Swab samples taken after day 5 had an average viral load of 3.44x105 copies per swab and a detection rate of $39.93 \%$. The last positive-testing swab sample was taken on day 28 post-onset. Average viral load in sputum was $7.00 \times 106$ copies per mL (maximum, 2.35x109 copies per mL) [8].

Apart from respiratory pathology, around one-fourth to one-third of the hospitalized patients in Wuhan (China), developed serious complications, such as arrhythmia and shock, and were therefore transferred to the intensive care unit (ICU) $[9,10]$.

Typical COVID-19 signs and symptoms include fever, cough, and shortness of breath [11]; potential atypical symptoms assessed included sore throat, chills, increased confusion, rhinorrhea or nasal 
congestion, myalgia, dizziness, malaise, headache, nausea, vomiting and diarrhea [12-14].

People of all ages are vulnerable to this new infectious disease, however elderly people and the existence of underlying comorbidities as cardiovascular disease, diabetes, hypertension, immunosuppression or hospitalization in the ICU [15], have a worse prognosis [10, 16]. According to the average age, in the early stage of the outbreak in Wuhan, it was 59 years [17], very similar to the data provided in Spain that, in 16th March 2020, with 710 analyzed cases, the median age was 51 years $[18,19]$, although the deaths were in $67.2 \%$ in elderly more 80 years old, in according Italian dates [20].

Crisis management in emergent public health event is a global problem and a difficult thesis for researchers worldwide, highlighted by World Health Organization for its vital importance to public sanitation and health, life quality and survival [21,22].

In many infectious diseases, from bacterial or viral origin, affect the respiratory tract, and therefore with the presence of pathogens in saliva, mouthwashes have been used to reduce the viral load. The chlorhexidine (CHX) is an broad spectrum antiseptic the most used daily in a dental clinic. However, there are many others on the market but, which is the best to out down the viral load? These rinses, are effective of the new viruses as COVID-19? The aim of this article is to analyze the published bibliography to know which mouthwash is effective to reduce the viral load of COVID-19 in the infected patients to minimize its virulence and therefore transmission person-person.

\section{Material and Methods}

This is not a systematic review but an update about the use of rinses to reduce de viral load in oral cavity of COVID-19, and try to analyze which is the most effective to avoid the transmission patientdentist or vice versa.

I looked for the publications in the last months that deal with coronavirus.

\section{Results and Discussion}

Mode of transmission is based, initially animal-to human and nowadays in sustained human-to-human spread [1]. The COVID-19 was recently identified in saliva of infected patients, and the 2019$\mathrm{nCoV}$ sequence could be also detected in the self-collected saliva of most infected patients even not in nasopharyngeal aspirate, and serial saliva specimens monitoring showed declines of salivary viral load after hospitalization [23].

This coronavirus can remain suspended in aerosols and retain infectivity for long periods with the possibility for to be inhaled or transmitted via direct contact with conjunctival, nasal, or oral mucosa of oral healthcare personnel (OHCP) or cross-contamination between patients. Although, some authors explain that spread of SARS-CoV-2 through aerosols or vertical transmission (from mothers to their newborns) has to be confirmed yet [24].

There are three different pathways for COVID-19 to present in saliva: firstly, in the lower and upper respiratory tract that enters the oral cavity together with the liquid droplets frequently exchanged by these organs; secondly, in the blood can access the mouth via crevicular fluid, an oral cavity-specific exudate that contains local proteins derived from extracellular matrix and serum-derived proteins [25, 26]. Finally, another way for coronavirus happens in the oral cavity is by major- and minor-salivary gland infection, with subsequent release of particles in saliva via salivary ducts, suggesting that salivary gland cells could be an important source of COVID-19 in saliva [26, 27]. In other words, the saliva droplets to be considered as a fundamental concept is the transmission of the virus [28].

It is now believed that its interpersonal transmission occurs mainly via respiratory droplets (cough, sneeze, droplets from Plügge) and contact transmission through nasal or ocular mucosa (The Chinese Preventive Medicine Association 2020), many times generated during dental clinical procedures is expected [26]. In addition, there may be risk of fecal-oral transmission, as researchers have identified SARSCoV-2 in the stool of patients from China and the United States Protocol of prevention.

Dental procedure generated aerosol is a potential source of cross-contamination in the dental office. In addition, to containing common oral bacteria it may include pathogenic bacteria, such as Mycobacterium tuberculosis or Legionella pneumophilia, and viruses such as HIV, hepatitis B or C virus, herpes simplex virus, influenza virus [29], and especially the virus that currently causing a global pandemic, COVID-19.

A recent study indicates that copper and paper can allow the virus to survive from 4 to over 24 hours. On the other hand, the infectious charge can be drastically reduced only after at least 48 hours for steel and 72 hours for plastic [30]. For this reason, it's more urgent to implement strict and efficient infection control protocols for dental practices and hospitals in countries/regions that are (potentially) affected with COVID-19, strict and effective infection control protocols are urgently required [3, 29].

Researchers calculated the mean incubation to be 6.4 days (ranges 2.1 to 11.1 days). It was estimated for travellers from Wuhan with confirmed 2019-nCoV infection in the early outbreak phase, using their reported travel histories and symptom onset dates. This is essential to epidemiological case definitions, and is required to determine the appropriate duration of quarantine [31]. Protection measures are needed to fight against COVID-19.

This emerging pandemic and its severe outbreak in the Italian population have induced the Italian Government first and then the European Union and in many countries of the world, to promote drastic impact measures to "flatten the curve" of the COVID-19 infection and in turn avoid health systems (in particular, intensive care units) being overwhelmed, resulting in fewer deaths [32]. The limitation of people circulating outside their home, social distance the stoppage of almost all working activities and the request to the population to use protective masks and gloves have the main goal of minimizing the likelihood that people who are not infected come into contact with others who are already infected and probably still asymptomatic [33]

Healthcare workers and other patients in the hospital are in 
close contact with patients with symptomatic and asymptomatic COVID-19, and for this reason they are at higher risk of SARS-CoV-2 infection.

As always happens, healthcare professionals have been immediately involved in the national emergency, overworking, often day and night: unfortunately, small numbers of them have also become infected, and some have tragically died [28].

In the early stage of the epidemic, in an analysis of 138 hospitalized patients with COVID- 19 in Wuhan, $41 \%$ were presumed to have been infected in hospital, including $29 \%$ health care workers and $12 \%$ patients hospitalized for other reasons [10].

As of 14th February 2020, a total of 1.716 health care workers in China were infected with SARS-CoV-2, consisting of 3.8\% affected patients [10]. Actually, (4th April, 2020), in Spain the healthcare workers infected are about 6.500 [34].

According to these statements Spagnolo et al. [28] wrote in an article that, on 15 March 2020, the New York Times published an article entitled "The Workers Who Face the Greatest Coronavirus Risk", where an impressive schematic figure described that dentists are the workers most exposed to the risk of being affected by COVID-19, much more than nurses and general physicians. For this reason, the dentists are often the first line of diagnosis, as they work in close contact with patients.

There should be action protocols, based on both existing guidelines and published research on the principles and practices to achieve control of dental infections, mainly addressing the characteristics of nosocomial infection, and SARS, in dental care settings, and providing recommendations on patient evaluation and infection control protocols in dentistry [3].

According to all these arguments, Meng et al. [29] published an article with relevant guidelines and research, recommending management protocols for dental practitioners and students in (potentially) affected areas, introducing the essential knowledge about COVID-19 and nosocomial infection in dental settings. For this reason, [29] established a protocol, since January 24, according to which they should only be attended at the School and Hospital of Stomatology, patients with emergent dental treatment need, under the premise of adequate protection measures. Procedures that are likely to induce coughing should be avoided (if possible) or performed cautiously [35].

Aerosol-generating procedures, such as the use of a 3-way syringe, should be minimized as much as possible. Moreover, rubber dams [36], and the use of saliva ejectors with a low volume or high volume can reduce the production of droplets and aerosols, or spatter in dental procedures of emergency $[28,37]$.

If an intraoral X-ray for a correct diagnosis is needed, a panoramic radiography or cone beam (CBCT), are appropriate alternatives during the outbreak of COVID-19, because the radiographic plate can stimulate saliva secretion and coughing [36].

Efficient infection control can prevent the virus from further spreading, which makes the epidemic situation under control. The most important protective measures according to Chinese experts consensus are: hand-cleaning- and medical-glove-related hand protection, mask- and goggles-related face protection, UV-related protection, eye protection, nasal and oral mucosa protection, outer ear and hair protection [37].

For this reason, and knowing that the risk of cross infection may be high among patients and oral healthcare practitioners in oral healthcare settings $[3,29]$, population must keep in mind the requirement of a close contact between healthcare workers and infected patients to collect nasopharyngeal or oropharyngeal samples, the possibility of a saliva self-collection can strongly reduce the risk of COVID-19 transmission [26].

Dental practice should be postponed at least 1 month for convalescing patients with SARS or infected with COVID-19. [29, 38].

Since the viral load contained in the human saliva is very high, rinses with antiseptic mouthwashes can only reduce the infectious amount but are not able to eliminate the virus in the saliva [29, 39]. Active virus replication in the upper respiratory tract puts the prospects of COVID-19 containment in perspective [7].

In this sense, a few important concepts would be useful to briefly report and discuss here or raise future research.

To reduce viral load, Samaranayake et al. [38] and the General Council of Dentists of Spain [40], based on the study of [39], recommended that the patient should must rinse during 1 minute, with a mouthwash of $1 \%$ hydrogen peroxide solution $1 \%$ o de $0.2 \%$ povidone-iodine (PVP-I) before urgent treatment [40], because for over 60 years, PVP-I formulations have been shown to limit the impact and spread of infectious diseases with potent antiviral, antibacterial and antifungal effects [41].

The solution 3\% hydrogen peroxide was used by author such as Nobahar et al. [42] in the prevention of VAP, obtaining good results in reducing the bacterial load and recommend its use in routine care for the prevention of this type of pneumonia. Nevertheless, [43] that applied $1.5 \%$ hydrogen peroxide solution with a suction brush after applying $0.12 \% \mathrm{CHX}$ oral solution using swab, in patients hospitalized in ICU, they did not get statistically significant differences comparing with the group control.

According to PVP-1, other authors, such as Meng et al. [29], advised that a preoperative concentration at $1 \%$ through gargle/ mouthwash reduced the viral load in the dental aerosol and in the oral cavity and oropharynx, and consequently, it is an effective way to reduce the risk of experiencing contamination in the dental office. In addition, we must include others hygiene measures needed to reduce the severity of future SARS outbreaks [44].

Marui et al. [45] analyzed the effect of some rinse such as Cetylpyridinium chloride (CPC) $0.05 \%$ only or combinated $(0.075 \%$ CPC, $0.28 \%$ zinc lactate, and $0.05 \%$ sodium fluoride), essential oils (like tea tree oil), CHX $0.12 \%$ or $0.2 \%$ and herbal mouthrinse, through the microbiological count of total number of colony-forming units (CFU). This number of CFU had a significant reduction $(\mathrm{p}<0.05)$ with a mean of $78.9 \%$ with CHX, $61.3 \%$ with essential oils and $61.2 \%$ 
with CPC. In this study, the use of a herbal mouthrinse did not result in a significant reduction in the number of CFU compared with the control product [45], however [46] obtained significant antibacterial effects against Staphylococcus aureus and Streptococcus pneumoniae, and for this reason it is an alternative to other rinses.

On the other hand, Koeman et al. obtained satisfactory results when combining CHX with colistin (polypeptide antibiotic effective against resistant bacteria), but both cases used only in the prevention of ventilator-associated pneumonia (VAP). Oral CHX has also not been seen as decreasing the bacterial load of COVID-19, as the Guideline for the Diagnosis and Treatment of Novel Coronavirus Pneumonia (the 5th edition) released by the National Health Commission of the People's Republic of China concludes that the most used rinses are those of CHX, may not be effective to kill 2019-nCoV.

Bioscience Laboratories (Bozeman, Montana 2016-2019) made a study to compare the virucidal effect of several oral rinses as iodine or CHX, obtaining efficacy to completely inactivate oral pathogens, taking 15 seconds and 30 seconds to inactivate coronavirus, where others products were ineffective [48]. Nevertheless, other studies describe to CLX as a poor and not effective antiviral agent against Coronavirus (Viruses, November 2012, 4, 3044-3068) [49], just as [50], said in their study: the virus is resistant to CHX, and therefore its use is not useful.

Li et al. [3] described the first typical family case of COVID-19 treated using the Chinese traditional patent medicine Shuanghuanglian oral liquid (SHL), because of poor response to the western medicine. If SHL used extracts of three Chinese herbs, namely, honeysuckle, forsythia, and Scutellaria baicalensis, to treat cold, sore throat, and cough with fever.

The most reviewed articles about COVID-19 do not considered the use of mouth rinses as a measure to reduce viral load and therefore the risk of transmission by Pügge drops from patient to dentist, or vice versa $[51,52]$.

\section{Conclusions}

A concentration of $1 \%-1.5 \%$ hydrogen peroxide solution or $1 \%$ $0.2 \%$ povidone-iodine seems to be an effective mouthwash to reduce the viral load in oral cavity.

To provide legal help, guidance and protocols to the oral medical industry in dealing with public health emergencies is essential. On this way, if traditional Chinese medicine and the use of some herbal rinses have been successful, research should be conducted along these lines. Perhaps we will face other viruses like hartavirus in the near future, and we must be prepared.

\section{Acknowledgments}

Health professionals for their continuous fight to stop this pandemic and researchers who are still looking for the vaccine against COVID-19.

Thanks to Chang Chen for translate Chinese texts, and I would like to say thank you, personally, Dra. Pía López Jornet for encouraging me to continue working and reading scientific literature, even if we are confined in Spain at these moments.

\section{Reference}

1. Chan JF, Yuan S, Kok KH, To KK, Chu H et al. (2020) A familial cluster of pneumonia associated with the 2019 novel coronavirus indicating person-to-person transmission: a study of a family cluster. Lancet 395: 514-523.

2. Fan J, Liu X, Pan W, Douglas MW, Bao S (2020) Epidemiology of 2019 novel coronavirus disease in Gansu Province, China 2020. Emerg Infect Dis. [crossref]

3. Li ZY, Meng LY (2020) The prevention and control of a new coronavirus infection in department of stomatology. Zhonghua Kou Qiang Yi Xue Za Zhi 55: E001. [crossref]

4. Olsen SJ, Chen MY, Liu YL, Witschi M, Ardoin A et al. (2020) European COVID-19 Work Group. Early Introduction of Severe Acute Respiratory Syndrome Coronavirus 2 into Europe. Emerg Infect Dis 26. [crossref]

5. European COVID-19 Work Group. European Centre of Desease Control. https:// www.ecdc.europa.eu/en/geographical-distribution-2019-ncov-cases [accessed 4th April 2020]

6. World Health Organization. 2020a. [Last update 4th April 2020]

7. Corman VM, Landt O, Kaiser M, Molenkamp R, Meijer A et al. (2020) Detection of 2019 novel coronavirus (2019-nCoV) by real-time RT-PCR. Euro Surveill 25. [crossref]

8. Wölfel R, Corman VM, Guggemos W, Seilmaier M, Zange S et al. (2020) Virological assessment of hospitalized patients with COVID-2019. Nature. [crossref]

9. Huang C, Wang Y, Li X, Ren L, Zhao J et al. (2020) Clinical features of patients infected with 2019 novel coronavirus in Wuhan, China. Lancet.

10. Wang D, Hu B, Hu C, Zhu F, Liu X et al. (2020) Clinical characteristics of 138 hospitalized patients with 2019 novel coronavirus-infected pneumonia in Wuhan, China. JAMA. [crossref]

11. CDC. Preparing for COVID-19: long-term care facilities, nursing homes. Atlanta, GA: US Department of Health and Human Services, CDC; 2020.

12. Kimball A, Hatfield KM, Arons M, James A, Taylor J et al. (2020) Public Health Seattle \& King County; CDC COVID-19 Investigation Team Asymptomatic and Presymptomatic SARS-CoV-2 Infections in Residents of a Long-Term Care Skilled Nursing Facility - King County, Washington, March 2020. MMWR Morb Mortal Wkly Rep 69: 377-381.

13. Guan W, Ni Z, Hu Y, Liang W, Ou C et al. (2020) For the China Medical Treatment Expert Group for Covid-19*. Clinical characteristics of 2019 novel coronavirus infection in China. $N$ Engl J Med.

14. Ding Q, Lu P, Fan Y, Xia Y, Liu M (2020) The clinical characteristics of pneumonia patients co-infected with 2019 novel coronavirus and influenza virus in Wuhan, China. J Med Virol. [crossref]

15. Cascella M, Rajnik M, Cuomo A, Dulebohn SC, Di Napoli R (2020) Features, Evaluation and Treatment Coronavirus (COVID-19). StatPearls [Internet]. Treasure Island (FL): StatPearls Publishing; 2020-2020 Mar 8. [crossref]

16. Yang Y, Lu Q, Liu M, Wang Y, Zhang A et al. (2020) Epidemiological and clinical features of the 2019 novel coronavirus outbreak in China. medRxiv.

17. Bassetti M, Vena A, Giacobbe DR (2020) The novel Chinese coronavirus (2019-nCoV) infections: Challenges for fighting the storm. Eur J Clin Invest 50: e13209. [crossref]

18. CNE (Centro Nacional de Estadística) (2020) Informe sobre la situación de COVID-19 en España. CNE. SiVies. CNM(ISCIII);

19. Spanish Ministry of Health. https://www.mscbs.gob.es/profesionales/saludPublica/ ccayes/alertasActual/nCov-China/home.htm

20. Italian Ministry of Health. http://www.salute.gov.it/portale/news/p3 2 1_1_1. jsp? lingua $=$ italiano $\&$ menu $=$ notizie $\& \mathrm{p}=$ dalministero $\& \mathrm{id}=4232 \quad[$ accessed $23 \mathrm{rd}$ March 2020]. Feb 24, JAMA 2020.

21. Shen SM (2020) Study on issues for stomatological institutions responding to state public health emergencies. Zhonghua Kou Qiang Yi Xue Za Zhi 55: E005. [crossref]

22. Mahase E (2020) China coronavirus: WHO declares international emergency as death toll exceeds 200. BMJ 368: $\mathrm{m} 408$. [crossref]

23. To KK, Tsang OT, Chik-Yan Yip C, Chan KH, Wu TC et al. (2020) Consistent detection of 2019 novel coronavirus in saliva. Clin Infect Dis. [crossref]

24. Guo YR, Cao QD, Hong ZS, Tan YY, Chen SD et al. (2020) The origin, transmission and clinical therapies on coronavirus disease 2019 (COVID-19) outbreak - an update on the status. Mil Med Res 7: 11. [crossref]

25. Zhu N, Zhang D, Wang W, Li X, Yang B et al. (2020) China Novel Coronavirus Investigating and Research Team. A novel coronavirus from patients with pneumonia in China. N Engl J Med 382: 727-733. [crossref] 
Juan Antonio Ruiz Roca (2020) What is the most effective mouthwash in patients infected with covid-19 to minimize possible transmission by saliva? Update.

26. Sabino-Silva R, Jardim ACG, Siqueira WL (2020) Coronavirus COVID-19 impacts to dentistry and potential salivary diagnosis. Clin Oral Investig 24: 1619-1621 [crossref]

27. Liu L, Wei Q, Alvarez X, Wang H, Du Y et al. (2011) Epithelial cells lining salivary gland ducts are early target cells of severe acute respiratory syndrome coronavirus infection in the upper respiratory tracts of rhesus macaques. J Virol 85: 4025-4030. [crossref]

28. Spagnuolo G, De Vito D, Rengo S, Tatullo M (2020) COVID-19 Outbreak: An Overview on Dentistry. Int J Environ Res Public Health 17. [crossref]

29. Meng L, Hua F, Bian Z (2020) Coronavirus Disease 2019 (COVID-19): Emerging and Future Challenges for Dental and Oral Medicine. J Dent Res 12: 22034520914246. [crossref]

30. van Doremalen N, Bushmaker T, Morris D, Holbrook M, Gamble A et al. (2020) Aerosol and surface stability of HCoV-19 (SARS-CoV-2) compared to SARS-CoV-1. N Engl J Med 382: 1564-1567 [crossref]

31. Backer JA, Klinkenberg D, Wallinga J (2020) Incubation period of 2019 novel coronavirus (2019-nCoV) infections among travellers from Wuhan, China, 20-28 January. Euro Surveill 25. [crossref]

32. Stevens, H. Why Outbreaks like Coronavirus Spread Exponentially, and How to "Flatten the Curve". Available online: https://www.washingtonpost.com/ graphics/2020/world/corona-simulator/?itid=hp_hp- top-table-main_virus-simulat or520pm\%3Ahomepage\%2Fstory-ans (accessed on 4th April 2020).

33. Li R, Pei S, Chen B, Song Y, Zhang T et al. (2020) Substantial undocumented infection facilitates the rapid dissemination of novel coronavirus (SARS-CoV2). Science. [crossref]

34. Instituto de Salud Carlos III. https://www.isciii.es/QueHacemos/Servicios/ VigilanciaSaludPublicaRENAVE/EnfermedadesTransmisibles/Documents/ INFORMES/Informes\%20COVID-19. Informe\%20n\%2020.\%20Situación\%20 de\%20COVID-19\%20en\%20España\%20a\%203\%20de\%20abril\%20de\%202020.pdf. [accessed 4th April 2020]

35. World Health Organization. 2020b. Clinical management of severe acute respiratory infection when novel coronavirus $(2019-\mathrm{nCoV})$ infection is suspected: interim guidance [23thMarch 2020].

36. Vandenberghe B, Jacobs R, Bosmans H (2020) Modern dental imaging: a review of the current technology and clinical applications in dental practice. Eur Radiol 20: 2637-2655. [crossref]

37. Yan Y, Chen H, Chen L, Cheng B, Diao P et al. (2020) Consensus of Chinese experts on protection of skin and mucous membrane barrier for healthcare workers fighting against coronavirus disease 2019. Dermatol Ther 13: e13310. [crossref]

38. Samaranayake L, Reid J, Evans D (1989) The efficacy of rubber dam isolation in reducing atmospheric bacterial contamination. ASDC J Dent Child 56: 442-444. [crossref]
39. Peng X, Xu X, Li Y, Cheng L, Zhou X et al. (2020) Transmission routes of 2019-nCoV and controls in dental practice. Int J Oral Sci 12: 9.

40. Informe técnico del Consejo General de Odontólogos y Estomatólogos de España (COEE). [accessed 26th March 2020]

41. Eggers M, Koburger-Janssen T, Eickmann M, Zorn J (2018) In Vitro Bactericidal and Virucidal Efficacy of Povidone-Iodine Gargle/Mouthwash Against Respiratory and Oral Tract Pathogens. Infect Dis Ther Jun 7: 249-259. [crossref]

42. Nobahar M, Razavi MR, Malek F, Ghorbani R (2016) Effects of hydrogen peroxide mouthwash on preventing ventilator-associated pneumonia in patients admitted to the intensive care unit. Braz J Infect Dis 20: 444-450. [crossref]

43. Scannapieco FA, Yu J, Raghavendran K, Vacanti A, Owens SI et al. (2009) A randomized trial of chlorhexidine gluconate on oral bacterial pathogens in mechanically ventilated patients. Crit Care 13: R117. [crossref]

44. Eggers M (2019) Infectious Disease Management and Control with Povidone Iodine. Infect Dis Ther 8: 581-593. [crossref]

45. Marui VC, Souto MLS, Rovai ES, Romito GA, Chambrone L et al. (2019) Efficacy of preprocedural mouthrinses in the reduction of microorganisms in aerosol: a systematic review. J Am Dent Assoc 150: 1015- 1026. [crossref]

46. Baradari AG, Khezri HD, Arabi S (2012) Comparison of antibacterial effects of oral rinses chlorhexidine and herbal mouth wash in patients admitted to intensive care unit. Bratisl Lek Listy 113: 556-560. [crossref]

47. Koeman M, van der Ven AJ, Hak E, Moore HC, Kaasjager K et al. (2006) Oral decontamination with chlorhexidine reduces the incidence of ventilator-associated pneumonia. Am J Respir Crit Care Med 173: 1348-1355. [crossref]

48. https://www.oralhealthgroup.com/features/molecular-iodine-could-this-be-a-gamechanger-for-dentistry/ [accessed 26th March 2020].

49. Geller C, Varbanov M, Duval RE (2012) Human coronaviruses: insights into environmental resistance and its influence on the development of new antiseptic strategies. Viruses 4: 3044-3068.

50. Kampf G, Todt D, Pfaender S, Steinmann E (2020) Persistence of coronaviruses on inanimate surfaces and their inactivation with biocidal agents. J Hosp Infect 104: 246251. [crossref]

51. Sohrabi C, Alsafi Z, O'Neill N, Khan M, Kerwan A et al. (2020) World Health Organization declares global emergency: A review of the 2019 novel coronavirus (COVID-19). Int J Surg 76: 71-76. [crossref]

52. Yu F, Du L, Ojcius DM, Pan C, Jiang S (2020) Measures for diagnosing and treating infections by a novel coronavirus responsible for a pneumonia outbreak originating in Wuhan, China. Microbes Infect 22: 74-79. [crossref] 